\title{
The impact of primary prophylaxis with granulocyte colony-stimulating factors on febrile neutropenia during chemotherapy: a systematic review and meta-analysis of randomized controlled trials
}

\author{
Li Wang • Onur Baser • Lucie Kutikova • John H. Page • \\ Richard Barron \\ Received: 21 October 2014 / Accepted: 23 February 2015 / Published online: 29 March 2015 \\ (C) The Author(s) 2015. This article is published with open access at Springerlink.com
}

\begin{abstract}
Purpose The study aims to assess the relative efficacy of granulocyte colony-stimulating factor (G-CSF) products administered as primary prophylaxis (PP) to patients with cancer receiving myelosuppressive chemotherapy.

Methods A systematic literature review identified publications (January 1990 to September 2013) of randomized controlled trials evaluating PP with filgrastim, pegfilgrastim, lenograstim, or lipegfilgrastim in adults receiving myelosuppressive chemotherapy for solid tumors or non-Hodgkin lymphoma. Direct, indirect, and mixed-treatment comparison (MTC) were used to estimate the odds ratio and $95 \%$ credible interval of febrile neutropenia (FN) during cycle 1 and all cycles of chemotherapy combined without adjusting for differences in relative dose intensity (RDI) between study treatment arms.

Results Twenty-seven publications representing 30 randomized controlled trials were included. Using MTC over all chemotherapy cycles, PP with filgrastim, pegfilgrastim,
\end{abstract}

Electronic supplementary material The online version of this article (doi:10.1007/s00520-015-2686-9) contains supplementary material, which is available to authorized users.

\section{Wang $(\triangle)$}

STATinMED Research, Inc.,

1400 Preston Rd, Suite 400, Plano, TX, USA

e-mail: lwang@statinmed.com

O. Baser

University of Michigan, Ann Arbor, MI, USA

L. Kutikova

Amgen Europe, Zug, Switzerland

J. H. Page $\cdot$ R. Barron

Amgen Inc., Thousand Oaks, CA, USA

O. Baser

STATinMED Research, Inc., Ann Arbor, MI, USA lenograstim, and lipegfilgrastim versus no G-CSF PP or placebo were associated with statistically significantly reduced FN risk. FN risk was also significantly reduced with pegfilgrastim PP versus filgrastim PP. Over all chemotherapy cycles, there was a numerical but statistically nonsignificant increase in the FN risk for lipegfilgrastim PP versus pegfilgrastim PP. Using MTC in cycle 1, PP with filgrastim, pegfilgrastim, and lipegfilgrastim versus no G-CSF PP or placebo were associated with statistically significantly reduced FN risk.

Conclusions In this meta-analysis, using MTC without adjustment for RDI, PP with all G-CSFs evaluated reduced the FN risk in patients receiving myelosuppressive chemotherapy. Future studies are needed to assess the influence of RDI on FN outcomes and to eliminate potential bias between G-CSF arms receiving more intensive chemotherapy than control arms.

Keywords Meta-analysis · Pegfilgrastim · Filgrastim . G-CSF · Febrile neutropenia $\cdot$ Lipegfilgrastim

\section{Introduction}

Febrile neutropenia $(\mathrm{FN})$ is a significant dose-limiting toxicity of myelosuppressive chemotherapy that may lead to reduced chemotherapy relative dose intensity (RDI) and increased FNrelated morbidity and mortality [1-5]. Although there is a risk of FN during any cycle of myelosuppressive chemotherapy, evidence from clinical trials and observational studies suggests that the greatest risk of FN is during the first cycle and that dose reductions and delays occur most frequently in subsequent cycles [2, 6-8].

Granulocyte colony-stimulating factors (G-CSFs) are glycoproteins that promote the growth and differentiation of 
neutrophil progenitor cells [9]. Pegfilgrastim and lipegfilgrastim (long-acting recombinant human G-CSFs) and filgrastim and lenograstim (short-acting recombinant human G-CSFs) are indicated to decrease the incidence of FN and severe neutropenia, as well as the duration of neutropenia or severe neutropenia, in patients receiving myelosuppressive chemotherapy [10-13]. Current guidelines recommend GCSF primary prophylaxis (PP) when the overall risk of FN among patients with non-myeloid malignancies receiving myelosuppressive chemotherapy is $20 \%$ or greater [14-16].

Clinical trials have shown that G-CSF PP reduces the risk of $\mathrm{FN}$, chemotherapy dose delays/reductions and reduced RDI, antibiotic use for FN-related infections, and acute FN-related hospitalization [7, 17-23]. Meta-analyses of clinical trial data have shown that G-CSF PP versus placebo is associated with reduction in infection-related and all-cause mortality [5, 24].

Three applications of meta-analysis are direct comparison, indirect comparison, and mixed-treatment comparison (MTC) of clinical trial evidence. Direct comparison is used for estimates based on direct evidence from head-to-head trials, and indirect comparison may be used when direct evidence is unavailable and indirect evidence from randomized controlled trials (RCTs) is being utilized. MTC is a generalized metaanalysis that offers greater statistical power by pooling direct and indirect evidence and assumes consistency between the two [25]. Using direct comparison, previous meta-analyses of RCTs have demonstrated a statistically significant reduction in the risk of FN following either filgrastim PP or pegfilgrastim PP versus no G-CSF, as well as pegfilgrastim PP versus filgrastim PP [26-28]. Using direct comparison or MTC, a statistically significant reduction in the risk of FN following lenograstim PP versus no G-CSF was demonstrated [26].

The primary objective of this systematic review and metaanalysis was to assess the relative efficacy of G-CSF (filgrastim, pegfilgrastim, lenograstim, or lipegfilgrastim) PP versus no G-CSF PP, placebo, or a comparator G-CSF product among patients with cancer receiving chemotherapy.

\section{Methods}

Data source and search strategy

A systematic literature review was performed to identify publications of RCTs published between January 1990 and September 2013. Electronic databases used in the systematic review were PubMed, EMBASE, Science Citation Index, Cochrane Database of Systematic Reviews, Cochrane central register of controlled clinical trials, Database of Abstracts of Reviews of Effects, Health Technology Assessment Database, and the National Health Services (NHS) Economic Evaluation Database, and manual searches of original publications. The search comprised subject headings and text with G-CSF product names or synonyms combined with a search filter to limit the results to RCTs (Online Resource 1).

Study selection and data extraction

Eligible studies included RCTs that compared PP with filgrastim, pegfilgrastim, lenograstim, or lipegfilgrastim with placebo, no G-CSF PP, or PP with a different G-CSF in adult patients receiving myelosuppressive chemotherapy for solid tumors or non-Hodgkin lymphoma. Patients initiated G-CSF PP 1 to 3 days after completion of myelosuppressive chemotherapy in each cycle. Control patients could receive secondary prophylaxis with G-CSF after the first cycle with the same myeloid growth factor. Studies were excluded if patients had received granulocyte-macrophage colony-stimulating factor, G-CSF for established FN, or different doses of the same GCSF in each treatment arm, and if patients had leukemia or multiple myeloma, or bone marrow or peripheral-blood stemcell transplantation. Studies were also excluded if they were economic analyses, evaluated investigational or unapproved drugs, or were published in languages other than English.

Two independent reviewers evaluated publications identified from the search and compared them with the search criteria to determine relevance; disagreements were resolved by consensus [29]. Key data (e.g., protocol design and patient, disease, and treatment characteristics) for each study were extracted (Online Resource 2).

\section{Study objectives}

The primary objective of this study was to assess the relative efficacy of PP with different G-CSFs in patients with cancer who received myelosuppressive chemotherapy in RCTs by performing meta-analyses using direct comparison, indirect comparison, and MTC in all chemotherapy cycles without adjustment for RDI. The secondary objective was to assess the relative efficacy of prophylaxis with the different GCSFs in the first cycle of chemotherapy only. An exploratory objective was to assess the relative efficacy of prophylaxis with the different G-CSFs by performing a meta-regression adjusting for RDI and other key FN risk factors as potential confounders that could affect $\mathrm{FN}$ risk.

Data synthesis and analysis

The primary study effect measure was the odds ratio (OR) of FN incidence. The treatment effects were determined using direct and indirect comparisons (inconsistency model) and MTC (consistency model), and reported as the OR (95\% credible interval [CrI]) of FN among filgrastim PP, pegfilgrastim PP, lenograstim PP, or lipegfilgrastim PP versus no G-CSF PP or placebo, and among each of the four G-CSFs as PP. ORs for each study and for conventional random-effects pairwise meta-analyses were 
calculated using Review Manager (RevMan5, Version 5.2; The Nordic Cochrane Centre, Copenhagen, Denmark). Statistical analyses were conducted in a Bayesian Markov chain Monte Carlo (MCMC) framework using the WinBUGS software. Posterior summaries were based on assessment of 50,000 simulations following an initial 50,000 simulations to allow burn-in [26, 30]. For Bayesian analysis, priors were predefined and then updated by using the data from the literature review. The resulting treatment effects were expressed as a posterior distribution. Specifically, the prior distribution for the population mean treatment effects was normal, with mean $=0$ and variance $=0.0001$. The prior distribution for individual treatment had a normal (mean= 0 , variance $=0.0001)$ prior on the $\log \mathrm{OR}$ of treatment and a uniform distribution $(0.2)$ prior on the standard deviation.

\section{Direct comparison}

When direct evidence was available, a random-effects model was used for direct comparisons to estimate the OR of FN incidence (treatment effect). Assumptions of this model are that the treatment effects in trials for each pairwise comparison were sampled from a random distribution of the trials. The OR of FN incidence with G-CSF PP versus no G-CSF and with comparisons between respective G-CSFs was assumed to be unrelated (i.e., consistency is not assumed). The randomeffects model is equivalent to separate meta-analyses for each relative treatment effect for head-to-head trials, except that a common between-trials variance term was assumed.

\section{Indirect comparison}

The effect of any pair of treatments was estimated using indirect evidence only. For example, the effect of $\mathrm{C}$ versus $\mathrm{B}\left(d_{\mathrm{BC}}\right)$ can be obtained from the estimates of the effect of $B$ versus $A$
$\left(d_{\mathrm{AB}}\right)$ and the effect of $\mathrm{C}$ versus $\mathrm{A}\left(d_{\mathrm{AC}}\right): d_{\mathrm{BC}}=d_{\mathrm{AC}}-d_{\mathrm{AB}}$. A Bayesian two-sided $P$ value of the null hypothesis (no difference between direct and indirect comparisons) was calculated by estimating the proportion of iterations where the direct estimate is larger than the indirect estimate of $\log \mathrm{OR}$.

\section{Mixed treatment comparison}

The MTC pooled the direct and indirect evidence to estimate the treatment effect. The MTC model assumed a single between-trial variance for each comparison. The OR of FN incidence with G-CSF PP versus no G-CSF PP and between G-CSFs assumed consistency between direct and indirect evidence $\left(d_{\mathrm{BC}}=d_{\mathrm{AC}}-d_{\mathrm{AB}}\right)$.

\section{Full meta-regression analysis and treatment effect with adjustment for RDI}

In RCTs of G-CSF PP versus placebo or no G-CSF PP, chemotherapy delays and dose reductions intended to reduce the risk of FN can lead to variability in exposure among the treatment arms, potentially resulting in significant within-study bias in the estimated ORs. This bias, which was not considered in the previous meta-analyses conducted by Madan et al. [26], could substantially mute the "real" clinical effect of GCSF, especially against placebo, and could vary between studies given differences in adherence and procedural controls of study treatments. Thus, a meta-regression of RCTs was planned to assess the influence of RDI and/or dose reduction/delay on the estimated treatment effect size. The full meta-regression was intended to assess the impact on treatment effect and to assess independent variables determined as important (e.g., cancer type, patient age, disease status [stage of disease or limited/extensive], chemotherapy regimen,

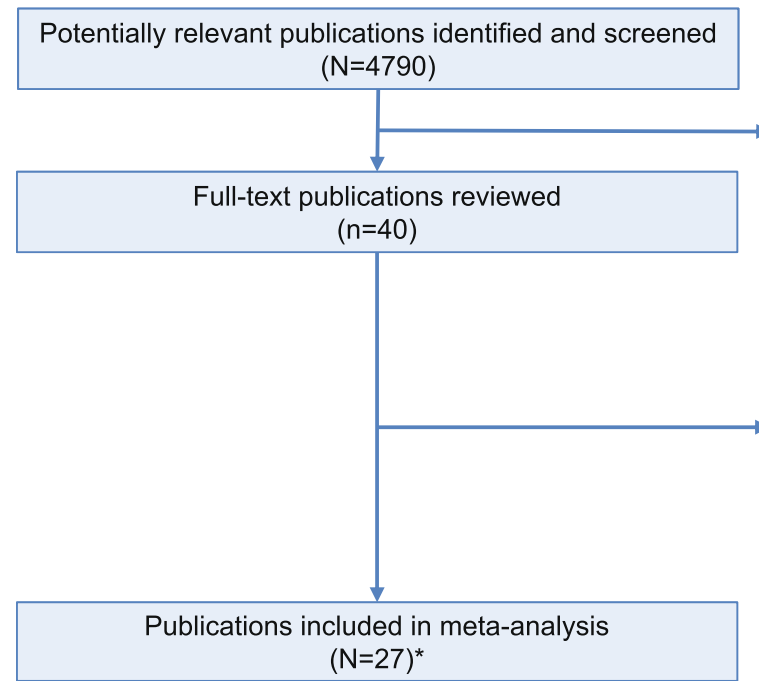

Publications excluded based on abstract review $(n=4750)$

Publications excluded based on full-text review $(n=13)$

- Not randomized controlled trial $(n=4)$

- Did not assess G-CSF ( $n=2)$

- Did not report FN incidence $(n=2)$

- Repeat of previous study $(n=2)$

- No comparison between G-CSFs or between G$\mathrm{CSF}$ and control $(n=1)$

- Stem cell transplantation $(n=1)$

- Differing drugs, dose, or schedule of chemotherapy within each arm $(n=1)$

$$
(\mathrm{N}=27)^{*}
$$

Fig. 1 Trial publication identification and selection. The 27 included publications reported data from 30 randomized controlled trials (asterisk). Data from three publications [32-34] were each counted as two studies 
chemotherapy regimen risk for $\mathrm{FN}$ [high, intermediate, or low per National Comprehensive Cancer Network guidelines [31]], number of cycles [maximum], cycle length, and RDI).

\section{Evaluation of heterogeneity}

Clinical heterogeneity was examined by evaluating variations in factors such as demographic characteristics, FN definition, cancer type, cycle length, G-CSF strategy, and allowed sample size. Between-trial statistical heterogeneity in the randomeffects model was assessed using the Inconsistency Index $\left(I^{2}\right)$, which estimates the proportion of the total variation among the treatment effect estimates that is due to heterogeneity.

\section{Results}

Of the initial 4790 publications screened, 40 qualified for full review. A total of 27 publications were included in the metaanalyses, with data from 30 RCTs (Fig. 1).

Meta-analysis of all chemotherapy cycles without adjustment for RDI

Of the 30 RCTs assessing G-CSF PP, 22 compared G-CSF PP with no G-CSF PP or placebo, and 8 compared PP among different G-CSFs (Fig. 2). Six RCTs compared filgrastim PP with pegfilgrastim PP, and two RCTs compared lipegfilgrastim PP with pegfilgrastim PP.

The risks of FN in RCTs assessing G-CSF PP in all cycles versus no G-CSF PP, placebo, or a different G-CSF are summarized in Fig. 3. Conventional random-effects pairwise metaanalyses were performed to calculate ORs for each trial. Heterogeneity among pairwise meta-analyses was moderate $\left(I^{2}\right.$ range $19-74 \%$ ), except for the comparisons of pegfilgrastim
Fig. 3 Risk of febrile neutropenia in all included trials of G-CSF PP in all cycles $(n=30) . B E P / E P$ etoposide and cisplatin, plus or minus bleomycin; $B O P / V I P-B$ bleomycin, vincristine, cisplatin/etoposide, ifosfamide, cisplatin, bleomycin; $C H O P$ cyclophosphamide, doxorubicin, vincristine, and prednisone; $C N O P$ cyclophosphamide, mitoxantrone, vincristine, and prednisone; EPAR European public assessment report; $G-C S F$ granulocyte colony-stimulating factor; $M-H$ Mantel-Haenszel; NHL non-Hodgkin lymphoma; $P P$ primary prophylaxis

PP versus filgrastim PP $\left(I^{2}=0\right)$ and lipegfilgrastim PP versus placebo (not estimable; $n=1 \mathrm{RCT}$ ).

\section{Direct comparison}

Using direct comparison, the risk of FN was statistically significantly reduced for pegfilgrastim PP versus no G-CSF PP or placebo (OR $0.24 ; 95 \%$ CrI 0.13-0.43), filgrastim PP versus no G-CSF PP or placebo (OR 0.42; $95 \%$ CrI 0.29-0.59), and lenograstim PP versus no G-CSF PP or placebo (OR 0.34; $95 \%$ CrI 0.18-0.61) (Table 1). There were no statistically significant differences for the other comparisons.

\section{Indirect comparison}

Using indirect comparison, the risk of FN was statistically significantly reduced for pegfilgrastim PP versus no G-CSF PP or placebo (OR 0.26; $95 \%$ CrI 0.13-0.55) and filgrastim PP versus no G-CSF PP or placebo (OR 0.38; 95 \% CrI 0.160.93 ) (Table 1). There were no statistically significant differences for the other comparisons. Using a Bayesian approach, the differences in the risk of FN between the direct and indirect comparisons were not statistically significant $(P>0.05)$ and provided no evidence to suggest overall inconsistency.

\section{Mixed-treatment comparison}

Using MTC, the risk of FN was statistically significantly reduced for pegfilgrastim PP versus no G-CSF PP or placebo
Fig. 2 Overview of data from randomized controlled trials on G-CSF PP included in the metaanalysis of all chemotherapy cycles without adjustment for relative dose intensity $(n=30)$. $G$-CSF granulocyte colonystimulating factor, $P P$ primary prophylaxis

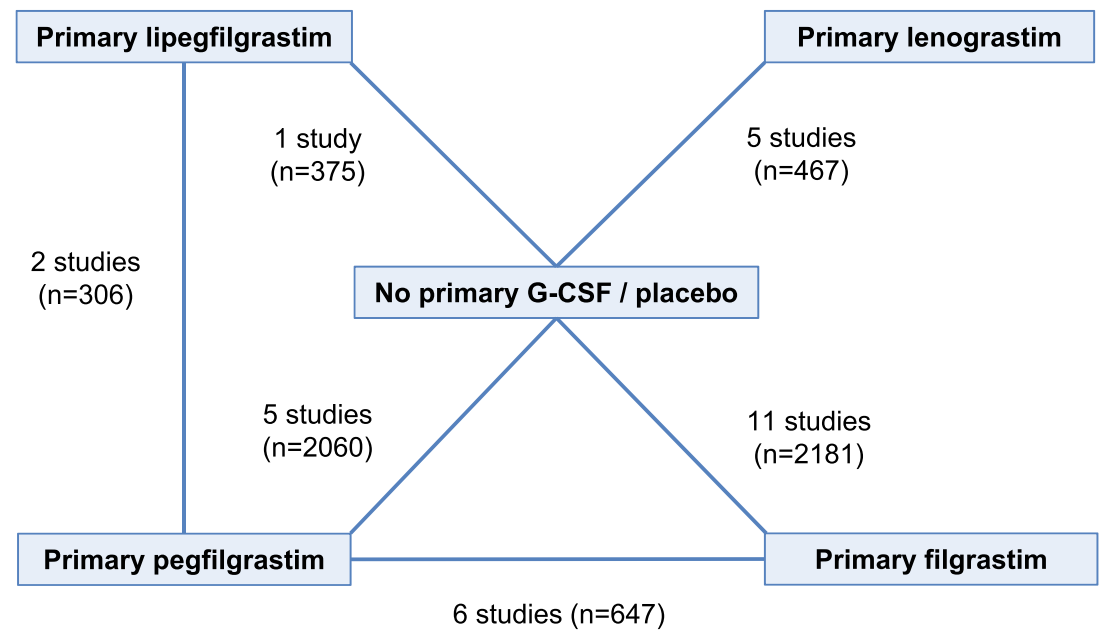


Control

Odds Ratio

Odds Ratio

Total Weight, \% M-H, Random $(95 \% \mathrm{Cl})$

$\mathrm{M}-\mathrm{H}$, Random $(95 \% \mathrm{Cl})$

\begin{tabular}{|c|c|c|c|}
\hline \multirow[b]{2}{*}{ Study or Subgroup } & \multicolumn{2}{|c|}{ Experimental } & \multirow{2}{*}{ Even } \\
\hline & Events & Total & \\
\hline \multicolumn{4}{|c|}{ Primary pegfilgrastim vs no primary G-CSF / placebo } \\
\hline Balducci et al 2007, NHL & 11 & 73 & 27 \\
\hline Balducci et al 2007, solid tumor & 14 & 343 & 34 \\
\hline Hecht et al 2010 & 4 & 124 & 11 \\
\hline Romieu et al 2007, cycle 1 & 4 & 30 & 5 \\
\hline Vogel et al 2005 & 6 & 463 & 78 \\
\hline Subtotal $(95 \% \mathrm{Cl})$ & & 1033 & \\
\hline Total events & 39 & & 155 \\
\hline \multicolumn{4}{|c|}{$\begin{array}{l}\text { Heterogeneity: } \mathrm{Tau}^{2}=0.58 ; \mathrm{Chi}^{2}=15.11 ; \mathrm{DF}=4(P=0.004) ; I^{2}=74 \% \\
\text { Test for overall effect: } Z=3.26 ; P=0.001\end{array}$} \\
\hline \multicolumn{4}{|c|}{ Primary filgrastim vs no primary G-CSF / placebo } \\
\hline Crawford et al 1991 & 38 & 95 & 80 \\
\hline del Giglio et al 2008 & 59 & 276 & 30 \\
\hline Doorduijin et al 2003 & 72 & 197 & 86 \\
\hline Fosså et al 1998, BEP/EP & 9 & 63 & 8 \\
\hline Fosså et al 1998, BOP/VIP-B & 16 & 65 & 30 \\
\hline Osby et al 2003, CHOP & 34 & 101 & 52 \\
\hline Osby et al 2003, CNOP & 40 & 125 & 62 \\
\hline Pettengell et al 1992 & 9 & 41 & 17 \\
\hline Timmer-Bonte et al 2005 & 16 & 90 & 27 \\
\hline Trillet-Lenoir et al 1993 & 17 & 65 & 34 \\
\hline Zinzani et al 1997 & 4 & 77 & 15 \\
\hline Subtotal $(95 \% \mathrm{Cl})$ & & 1195 & \\
\hline
\end{tabular}

Total events

Heterogeneity: $\mathrm{Tau}^{2}=0.09 ; \mathrm{Chi}^{2}=18.48 ; \mathrm{DF}=10(P=0.05) ; I^{2}=46 \%$

Test for overall effect: $Z=6.10 ; P<0.00001$

Primary lenograstim vs no primary G-CSF / placebo

Bui et al 1995, cycle $1 \quad 5 \quad 22$

Chevallier et al 1995

$36 \quad 61$

Gebbia et al 1993

Gebbia et al 1994

Gisselbrecht et al 1997

$5 \quad 43$

$5 \quad 23$

Total events

$\begin{array}{lc}\text { Total events } & 103 \\ \text { Heterogeneity: } \mathrm{Tau}^{2}=0.05 ; \mathrm{Chi}^{2}=4.92 ; \mathrm{DF}=4 & (P=0.30) ; I^{2}=19 \%\end{array}$

$\begin{array}{ll}73 & 3.9\end{array}$

343

117

29

465

1027

4.8

4.8
2.4

1.8

1.8
3.7

16.6 55

Test for overall effect: $Z=4.11 ; P<0.0001$

Primary pegfilgrastim vs primary filgrastim

$\begin{array}{lcc}\text { Green et al 2003 } & 10 & 77 \\ \text { Grigg et al 2003 } & 0 & 14 \\ \text { Holmes et al 2002, phase 2 } & 5 & 46 \\ \text { Holmes et al 2002, phase 3 } & 14 & 149 \\ \text { Park et al 2013, cycle 1 } & 1 & 20 \\ \text { Vose et al 2003 } & 6 & 29 \\ \text { Subtotal (95\% CI) } & & 335 \\ \text { Total events } & 36 & \end{array}$

Heterogeneity: $\mathrm{Tau}^{2}=0.00 ; \mathrm{Chi}^{2}=2.56 ; \mathrm{DF}=5(P=0.77) ; I^{2}=0 \%$

Test for overall effect: $Z=2.15 ; P=0.03$

Primary lipegfilgrastim vs no primary G-CSF / placebo

Lipeg vs con Lonquex EPAR $\quad 10 \quad 250$

Subtotal $(95 \% \mathrm{Cl})$

Total events

250

10

$\begin{array}{ccc}15 & 26 & 2.2 \\ 42 & 59 & 4.1 \\ 14 & 43 & 2.6 \\ 18 & 28 & 2.2 \\ 62 & 80 & 4.5 \\ & \mathbf{2 3 6} & \mathbf{1 5 . 5}\end{array}$

$0.22(0.06-0.76)$

$0.58(0.27-1.25)$

$0.27(0.09-0.84)$

$0.15(0.04-0.54)$

$0.50(0.25-1.00)$

$0.37(0.23-0.60)$

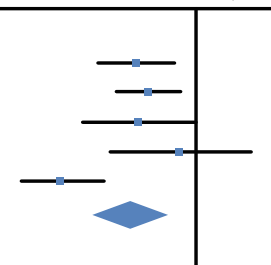

$125 \quad 3.4$

$0.48(0.19-1.18)$

$.60(0.25-1.43)$

$0.29(0.01-7.70)$

$1.40(0.25-7.81)$

$0.46(0.23-0.92)$

$0.50(0.04-5.99)$

$1.09(0.31-3.85)$

$0.60(0.38-0.96)$

$0.48(0.19-1.18)$
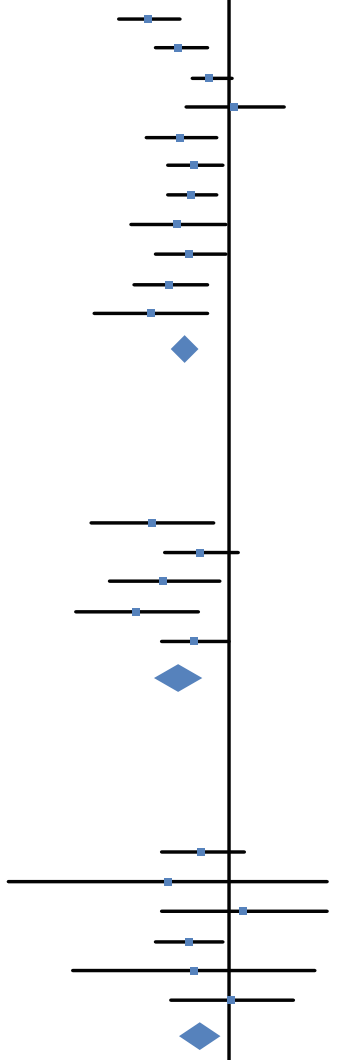

Heterogeneity: Not applicable

Test for overall effect: $Z=1.59 ; P=0.11$

Primary lipegfilgrastim vs primary pegfilgrastim

Lipeg vs peg Lonquex EPAR
Lipeg vs peg, Bondarenko et al 2013

Subtotal $(95 \% \mathrm{CI})$

$6 \quad 50$

$50-4$

$54 \quad 2.0$

Total events

$7 \quad 151$

Heterogeneity: $\mathrm{Tau}^{2}=0.47 ; \mathrm{Chi}^{2}=1.51 ; \mathrm{DF}=1(P=0.22) ; I^{2}=34 \%$

Test for overall effect: $Z=0.03 ; P=0.98$

Total $(95 \% \mathrm{Cl})$

3195

Total events

$509 \quad 817$

2841

$1.70(0.45-6.43)$

$0.33(0.03-3.19)$

$0.98(0.21-4.53)$

$155 \quad 2.8$

Heterogeneity: $\mathrm{Tau}^{2}=0.15 ; \mathrm{Chi}^{2}=54.13 ; \mathrm{DF}=29(P=0.003) ; I^{2}=46 \%$

Test for overall effect: $Z=8.00 ; P<0.00001$

Test for subgroup differences: $\mathrm{Chi}^{2}=4.84 ; \mathrm{DF}=5(P=0.44) ; I^{2}=0 \%$

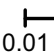

Favors experimental arm Favors 100 
Table 1 Posterior odds ratios for febrile neutropenia from all cycles with and without the assumption of consistency (30 trials, 60 arms)

\begin{tabular}{|c|c|c|c|c|}
\hline \multirow[t]{2}{*}{ Treatment contrast $^{\mathrm{a}}$} & \multicolumn{3}{|c|}{ Consistency not assumed } & \multirow{2}{*}{$\frac{\text { Consistency assumed }}{\text { Combined (MTC) OR }(95 \% \mathrm{CrI})}$} \\
\hline & Direct OR (95\% CrI) & Indirect OR $(95 \% \mathrm{CrI})$ & $P$ value ${ }^{\mathrm{b}}$ & \\
\hline Pegfilgrastim PP vs no G-CSF PP or placebo & $0.24(0.13-0.43)$ & $0.26(0.13-0.55)$ & 0.58 & $0.25(0.17-0.40)$ \\
\hline Filgrastim PP vs no G-CSF PP or placebo & $0.42(0.29-0.59)$ & $0.38(0.16-0.93)$ & 0.42 & $0.42(0.30-0.57)$ \\
\hline Lenograstim PP vs no G-CSF PP or placebo & $0.34(0.18-0.61)$ & N/A & N/A & $0.34(0.19-0.60)$ \\
\hline Pegfilgrastim PP vs filgrastim PP & $0.63(0.33-1.22)$ & $0.57(0.29-1.15)$ & 0.42 & $0.61(0.40-0.98)$ \\
\hline Lipegfilgrastim PP vs no G-CSF PP or placebo & $0.48(0.13-1.74)$ & $0.24(0.06-1.02)$ & 0.24 & $0.35(0.14-0.88)$ \\
\hline Lipegfilgrastim PP vs pegfilgrastim PP & $1.00(0.26-3.79)$ & $2.00(0.47-8.11)$ & 0.76 & $1.39(0.54-3.50)$ \\
\hline
\end{tabular}

Bayesian methods used to obtain meta-analysis data

$C r I$ credible interval, $G$ - $C S F$ granulocyte colony-stimulating factor, $M T C$ mixed-treatment comparison, $N / A$ not available, $O R$ odds ratio, $P P$ primary prophylaxis

${ }^{\text {a }}$ Median OR values are shown unless indicated otherwise

${ }^{\mathrm{b}}$ Bayesian $P$ value determined based on comparison of direct and indirect evidence

(OR 0.25; $95 \%$ CrI 0.17-0.40), filgrastim PP versus no GCSF PP or placebo (OR 0.42; $95 \%$ CrI 0.30-0.57), lenograstim PP versus no G-CSF PP or placebo (OR 0.34; $95 \%$ CrI 0.19-0.60), pegfilgrastim PP versus filgrastim PP (OR 0.61; $95 \%$ CrI 0.40-0.98), and lipegfilgrastim PP versus no G-CSF PP or placebo (OR 0.35; $95 \%$ CrI 0.14-0.88) (Table 1). The risk of FN was numerically higher but statistically nonsignificant for lipegfilgrastim PP versus pegfilgrastim PP (OR 1.39; 95 \% CrI 0.54-3.50).

As expected, the values of the treatment effect estimates using MTC, which assumed consistency, were between those of the direct and indirect estimates. In all analyses, the root mean square differences (direct and indirect 60.18; MTC $60.01)$ were consistent with the number of data points $(60$ study arms), indicating a lack of differentiation between the models.

Meta-analysis of the first cycle of chemotherapy without adjustment for RDI

Of the 30 RCTs included, 19 had available data from the first cycle of chemotherapy (Table 2). Using MTC, FN risk in the first cycle was statistically significantly reduced for pegfilgrastim PP versus no G-CSF PP or placebo (OR 0.25; $95 \%$ CrI 0.13-0.50), filgrastim PP versus no G-CSF PP or placebo (OR 0.43; $95 \%$ CrI 0.24-0.76), and lipegfilgrastim PP versus no G-CSF PP or placebo (OR 0.25; 95 \% CrI 0.07$0.88)$. There were no statistically significant differences in the risk of FN for the rest of the comparisons (Online Resource 3).

The results for the first cycle of chemotherapy were generally consistent with those from all cycles. The differences in the risk of FN between the direct and indirect comparisons were not statistically significant $(P>0.05)$ and provided no evidence to suggest overall inconsistency.

In all analyses, the root mean squared differences (direct and indirect 36.44; MTC 36.26) were consistent with the number of data points (38 study arms), indicating a lack of differentiation between the models.

Meta-analysis of all cycles with adjustment for RDI

A minimum of 10 studies for each study-level variable has been suggested as the lowest number of studies for metaregression [50, 51]. In this study, the meta-regression analysis adjusting for RDI could not be conducted because only 10 RCTs overall (8 comparing filgrastim PP versus no G-CSF and 2 comparing lenograstim PP versus no G-CSF) contained RDI information that could be included in the model (Table 2 and Online Resource 4).

Full meta-regression of all cycles

The explanatory variables in the studies used for the metaregression analysis are described in Online Resource 4. There was insufficient reporting of most of the variables predictive of FN risk within trials needed to conduct a full metaregression; age was the most commonly and consistently reported variable.

\section{Discussion}

G-CSF PP has been shown to reduce the risk of FN and FNrelated hospitalization in patients receiving myelosuppressive chemotherapy for cancer [7, 16-21]. The reduction in FN incidence by G-CSF, however, can potentially be confounded by the delays in chemotherapy administration and the reduced dosing of chemotherapy that are intended to reduce the risk of FN. These delays and dose reductions often result in lower chemotherapy RDI in the control arm of RCTs and may lead to an underestimation of the potential treatment effect. Secondary prophylaxis after the first cycle of chemotherapy in 
Table 2 Included studies and data reported for chemotherapy cycle and relative dose intensity

\begin{tabular}{|c|c|c|c|c|}
\hline Study & All cycles & First cycle & RDI information & Meta-regression \\
\hline Balducci et al. 2007 (NHL) [32] & $\checkmark$ & $\checkmark$ & & \\
\hline Balducci et al. 2007 (solid tumor) [32] & $\checkmark$ & $\checkmark$ & & \\
\hline Hecht et al. 2010 [22] & $\checkmark$ & & & \\
\hline Romieu et al. 2007 (cycle 1) [35] & $\checkmark$ & $\checkmark$ & & \\
\hline Vogel et al. 2005 [7] & $\checkmark$ & $\checkmark$ & & \\
\hline Crawford et al. 1991 [17] & $\checkmark$ & $\checkmark$ & & \\
\hline del Giglio et al. 2008 [36] & $\checkmark$ & $\checkmark$ & & \\
\hline Doorduijin et al. 2003 [37] & $\checkmark$ & & $\checkmark$ & \\
\hline Fosså et al. 1998 (BEP/EP) [33] & $\checkmark$ & & $\checkmark$ & \\
\hline Fosså et al. 1998 (BOP/VIP-B) [33] & $\checkmark$ & & $\checkmark$ & \\
\hline Osby et al. 2003 (CHOP) [34] & $\checkmark$ & $\checkmark$ & $\checkmark$ & \\
\hline Osby et al. 2003 (CNOP) [34] & $\checkmark$ & $\checkmark$ & $\checkmark$ & \\
\hline Pettengell et al. 1992 [19] & $\checkmark$ & & $\checkmark$ & \\
\hline Timmer-Bonte et al. 2005 [38] & $\checkmark$ & $\checkmark$ & & \\
\hline Trillet-Lenoir et al. 1993 [39] & $\checkmark$ & $\checkmark$ & $\checkmark$ & \\
\hline Zinzani et al. 1997 [40] & $\checkmark$ & & $\checkmark$ & \\
\hline Bui et al. 1995 (cycle 1) [41] & $\checkmark$ & $\checkmark$ & & \\
\hline Chevallier et al. 1995 [42] & $\checkmark$ & & & \\
\hline Gebbia et al. 1993 [43] & $\checkmark$ & & $\checkmark$ & \\
\hline Gebbia et al. 1994 [44] & $\checkmark$ & & & \\
\hline Gisselbrecht et al. 1997 [18] & $\checkmark$ & & $\checkmark$ & \\
\hline Green et al. 2003 [21] & $\checkmark$ & $\checkmark$ & & \\
\hline Grigg et al. 2003 [45] & $\checkmark$ & $\checkmark$ & & \\
\hline Holmes et al. 2002 (phase 2) [46] & $\checkmark$ & $\checkmark$ & & \\
\hline Holmes et al. 2002 (phase 3) [20] & $\checkmark$ & $\checkmark$ & & \\
\hline Park et al. 2013 (cycle 1) [47] & $\checkmark$ & $\checkmark$ & & \\
\hline Vose et al. 2003 [48] & $\checkmark$ & & & \\
\hline Lonquex EPAR 2013 (lipegfilgrastim vs placebo) [49] & $\checkmark$ & $\checkmark$ & & \\
\hline Lonquex EPAR 2013 (lipegfilgrastim vs pegfilgrastim) [49] & $\checkmark$ & $\checkmark$ & & \\
\hline Bondarenko et al. 2013 [23] & $\checkmark$ & $\checkmark$ & & \\
\hline
\end{tabular}

Additional information on these studies is provided in Online Resource 4

$B E P / E P$ etoposide and cisplatin, plus or minus bleomycin; $B O P / V I P-B$ bleomycin, vincristine, cisplatin/etoposide, ifosfamide, cisplatin, and bleomycin; $C H O P$ cyclophosphamide, doxorubicin, vincristine, and prednisone; $C N O P$ cyclophosphamide, mitoxantrone, vincristine, and prednisone; EPAR European public assessment report; $N H L$ non-Hodgkin lymphoma; $R D I$ relative dose intensity.

RCTs may also diminish the estimates of G-CSF treatment effects. Because of the potential for such bias, this metaanalysis was designed to assess the risk of FN during the first chemotherapy cycle, as well as across all cycles.

There were several notable findings in this meta-analysis. First, there was a significant reduction in FN risk following PP with pegfilgrastim, filgrastim, or lenograstim compared with controls, confirming the results of previous metaanalyses [26-28]. Second, in contrast with the meta-analysis by Madan et al. [26], our MTC demonstrated a statistically significant reduction in FN risk for pegfilgrastim PP versus filgrastim PP. This difference may be due to the inclusion in the current analysis of an additional RCT that compared filgrastim to a biosimilar of pegfilgrastim [47]. Third, using
MTC, there was a statistically significant reduction in FN risk with lipegfilgrastim versus placebo. Fourth, the MTC showed a numerically higher but not statistically significant likelihood of FN reduction in favor of pegfilgrastim versus lipegfilgrastim. Finally, consistent with the results across all chemotherapy cycles, the MTC showed that PP with pegfilgrastim, filgrastim, and lipegfilgrastim significantly reduced the risk of FN during the first cycle of chemotherapy. The relatively small sample of studies that met inclusion criteria for the MTC $(n=19)$ may explain the convergent results and wide CrIs when compared with the result of the MTC analysis of objective 1 (all chemotherapy cycles without adjustment for RDI).

Only three studies provided direct evidence for the effectiveness of lipegfilgrastim PP [49]: lipegfilgrastim PP versus 
pegfilgrastim PP in a phase 2 and a phase 3 study in breast cancer patients receiving doxorubicin and docetaxel, and lipegfilgrastim versus placebo in a phase 3 study in patients with non-small-cell lung cancer receiving cisplatin/etoposide [49]. More evidence is required for lipegfilgrastim PP given the relatively limited number of studies, tumor types, and chemotherapy agents on the treatment effect of lipegfilgrastim PP and given the lack of significant findings in the placebocontrolled study [49].

One of the goals of this meta-analysis was to assess the impact of chemotherapy RDI on RCT treatment effect estimates and challenge the assumptions that the consistency of treatment effects is reasonable. It is possible that heterogeneity exists between the included studies and that the individual treatment effects were biased because of factors such as study-related imbalances in delivered dose intensity and number of chemotherapy cycles. The inability to adjust our analyses for RDI and other key factors affecting FN because of insufficient data highlights the need for more complete reporting of RDI in clinical trials, which would allow a more adequate assessment of the assumptions of consistency in the models used. Others have reported on some of these limitations in oncology studies, including reporting of drug use, outcomes, and other critical data that are required to justify assumptions of consistency and heterogeneity [24, 27, 28].

Although Cochrane Collaborations states that direct evidence should have a higher rating in the evidence hierarchy than indirect evidence [50], it is challenging to construct a coherent and internally consistent analysis for multiple treatments based on incremental effect size. To model variation between trials, the Bayesian MCMC method allowed us to fit a random-effects model assuming an independent normal distribution for relative treatment effect (log OR) and homogeneous variance $\left(\sigma^{2}\right)$ across all treatments. This is a reasonable model under the assumption that the evidence for all treatment comparisons is homogeneous.

This systematic review and meta-analysis had several limitations. Publications that were not indexed would not have been captured, potentially reducing the number of included trials. Although unlikely in the current study based on the existing state of knowledge for G-CSF PP, publication bias may have occurred if the published research was systematically unrepresentative of the population of completed studies. Unreported differences among studies (e.g., treatment allocation, blinding, and handling of withdrawals) may have biased the results of the study, possibly limiting the extent of generalization between study results. Because patient-level information was not available, outcomes of individual patients could not be reclassified to a common definition of FN, potentially increasing trial heterogeneity in the meta-analysis. Although unrelated to the study selection process, patients in control arms may have received secondary prophylaxis with G-CSF in later cycles or had changes in treatments (e.g., chemotherapy dose reductions), potentially biasing the reported treatment effect of a G-CSF. Finally, the planned metaregression analysis including RDI and other patient-level FN risk factors could not be performed because of an insufficient number of trials reporting patient-level data or reporting the data in a homogeneous manner for pooled analysis.

In conclusion, this meta-analysis confirmed previous observations [26-28] that G-CSF PP reduces the risk of FN in patients receiving myelosuppressive chemotherapy. The risk of FN was reduced with pegfilgrastim PP, filgrastim PP, lenograstim PP, and lipegfilgrastim PP when compared with no G-CSF PP or placebo. Additionally, compared with filgrastim PP, pegfilgrastim PP significantly reduced FN risk $(\mathrm{OR}=0.61 ; 95 \% \mathrm{CrI} 0.40-0.98)$. Over all chemotherapy cycles, there was a numerically higher but statistically nonsignificant increase in the FN risk for lipegfilgrastim PP versus pegfilgrastim PP (OR 1.39; $95 \%$ CrI 0.54-3.50); a statistically significant difference was not expected because of the small sample size $(n=306)$ for lipegfilgrastim (two studies). The effectiveness of G-CSF PP in preventing FN may have been underestimated because of various confounding factors including differences in received chemotherapy RDI between treatment arms and differences in the treatment approaches by healthcare practitioners. Given that reduced chemotherapy $\mathrm{RDI}$ is a risk factor for the development of FN and ultimately influences patient outcomes, it is important that patient-level data on RDI be reported in future studies assessing G-CSF PP, particularly because of the potential for confounding due to differences in RDI between treatment groups.

Acknowledgments The authors thank James Balwit, MS, and Patrick Little, $\mathrm{PhD}$, whose work was funded by Amgen Inc., for assistance in the preparation of this manuscript.

Conflict of interest LW: employment by STATinMED Research, a paid consultant to Amgen Inc.

OB: employment by STATinMED Research, a paid consultant to Amgen Inc.

LK: employment and stock ownership in Amgen Europe.

JP: employment and stock ownership in Amgen Inc.

RB: employment and stock ownership in Amgen Inc.

Open Access This article is distributed under the terms of the Creative Commons Attribution Noncommercial License which permits any noncommercial use, distribution, and reproduction in any medium, provided the original author(s) and the source are credited.

\section{References}

1. Kuderer NM, Dale DC, Crawford J, Cosler LE, Lyman GH (2006) Mortality, morbidity, and cost associated with febrile neutropenia in adult cancer patients. Cancer 106:2258-2266

2. Lyman GH, Dale DC, Crawford J (2003) Incidence and predictors of low dose-intensity in adjuvant breast cancer chemotherapy: a nationwide study of community practices. J Clin Oncol 21:4524-4531 
3. Lyman GH, Dale DC, Friedberg J, Crawford J, Fisher RI (2004) Incidence and predictors of low chemotherapy dose-intensity in aggressive non-Hodgkin's lymphoma: a nationwide study. J Clin Oncol 22:4302-4311

4. Lyman GH (2006) Chemotherapy dose intensity and quality cancer care. Oncology (Williston Park) 20:16-25

5. Lyman GH, Dale DC, Culakova E, Poniewierski MS, Wolff DA, Kuderer NM, Huang M, Crawford J (2013) The impact of the granulocyte colony-stimulating factor on chemotherapy dose intensity and cancer survival: a systematic review and meta-analysis of randomized controlled trials. Ann Oncol 24:2475-2484

6. Crawford J, Dale DC, Kuderer NM, Culakova E, Poniewierski MS, Wolff D, Lyman GH (2008) Risk and timing of neutropenic events in adult cancer patients receiving chemotherapy: the results of a prospective nationwide study of oncology practice. J Natl Compr Canc Netw 6:109-118

7. Vogel CL, Wojtukiewicz MZ, Carroll RR, Tjulandin SA, BarajasFigueroa LJ, Wiens BL, Neumann TA, Schwartzberg LS (2005) First and subsequent cycle use of pegfilgrastim prevents febrile neutropenia in patients with breast cancer: a multicenter, double-blind, placebo-controlled phase III study. J Clin Oncol 23:1178-1184

8. Culakova E, Thota R, Poniewierski MS, Kuderer NM, Wogu AF, Dale DC, Crawford J, Lyman GH (2014) Patterns of chemotherapy-associated toxicity and supportive care in US oncology practice: a nationwide prospective cohort study. Cancer Med 3:434-444

9. Groopman JE, Molina JM, Scadden DT (1989) Hematopoietic growth factors. Biology and clinical applications. N Engl J Med 321:1449-1459

10. Neulasta ${ }^{\circledR}$ (pegfilgrastim) (2012) Full prescribing information. Amgen Inc., Thousand Oaks, CA

11. Neupogen ${ }^{\circledR}$ (filgrastim) (2013) Full prescribing information. Amgen Inc., Thousand Oaks, CA

12. Lonquex ${ }^{\circledR}$ (lipegfilgrastim) (2013) Full prescribing information. Teva Pharma B.V., Utrecht, The Netherlands

13. Granocyte ${ }^{\circledR}$ (lenograstim) (2013) Full prescribing information. Chugai Pharma UK Limited, London, UK

14. Smith TJ, Khatcheressian J, Lyman GH, Ozer H, Armitage JO, Balducci L, Bennett CL, Cantor SB, Crawford J, Cross SJ, Demetri G, Desch CE, Pizzo PA, Schiffer CA, Schwartzberg L, Somerfield MR, Somlo G, Wade JC, Wade JL, Winn RJ, Wozniak AJ, Wolff AC (2006) 2006 update of recommendations for the use of white blood cell growth factors: an evidence-based clinical practice guideline. J Clin Oncol 24:3187-3205

15. Crawford J, Caserta C, Roila F, ESMO Guidelines Working Group (2010) Hematopoietic growth factors: ESMO Clinical Practice Guidelines for the applications. Ann Oncol 21:v248-v251

16. Aapro MS, Bohlius J, Cameron DA, Dal Lago L, Donnelly JP, Kearney N, Lyman GH, Pettengell R, Tjan-Heijnen VC, Walewski J, Weber DC, Zielinski C, European Organisation for Research and Treatment of Cancer (2011) 2010 update of EORTC guidelines for the use of granulocyte-colony stimulating factor to reduce the incidence of chemotherapy-induced febrile neutropenia in adult patients with lymphoproliferative disorders and solid tumours. Eur J Cancer 47:8-32

17. Crawford J, Ozer H, Stoller R, Johnson D, Lyman G, Tabbara I, Kris M, Grous J, Picozzi V, Rausch G, Smith R, Gradishar W, Yahanda A, Vincent M, Stewart M, Glaspy J (1991) Reduction by granulocyte colonystimulating factor of fever and neutropenia induced by chemotherapy in patients with small-cell lung cancer. N Engl J Med 325:164-170

18. Gisselbrecht C, Haioun C, Lepage E, Bastion Y, Tilly H, Bosly A, Dupriez B, Marit G, Herbrecht R, Deconinck E, Marolleau JP, Yver A, Dabouz-Harrouche F, Coiffier B, Reyes F (1997) Placebo-controlled phase III study of lenograstim (glycosylated recombinant human granulocyte colony-stimulating factor) in aggressive non-Hodgkin's lymphoma: factors influencing chemotherapy administration. Groupe d'Etude des Lymphomes de l'Adulte. Leuk Lymphoma 25:289-300

19. Pettengell R, Gurney H, Radford JA, Deakin DP, James R, Wilkinson PM, Kane K, Bentley J, Crowther D (1992) Granulocyte colony- stimulating factor to prevent dose-limiting neutropenia in non-Hodgkin's lymphoma: a randomized controlled trial. Blood 80:1430-1436

20. Holmes FA, O'Shaughnessy JA, Vukelja S, Jones SE, Shogan J, Savin M, Glaspy J, Moore M, Meza L, Wiznitzer I, Neumann TA, Hill LR, Liang BC (2002) Blinded, randomized, multicenter study to evaluate single administration pegfilgrastim once per cycle versus daily filgrastim as an adjunct to chemotherapy in patients with high-risk stage II or stage III/IV breast cancer. J Clin Oncol 20: 727-731

21. Green MD, Koelbl H, Baselga J, Galid A, Guillem V, Gascon P, Siena S, Lalisang RI, Samonigg H, Clemens MR, Zani V, Liang BC, Renwick J, Piccart MJ, the International Pegfilgrastim 749 Study Group (2003) A randomized double-blind multicenter phase III study of fixed-dose single-administration pegfilgrastim versus daily filgrastim in patients receiving myelosuppressive chemotherapy. Ann Oncol 14:29-35

22. Hecht JR, Pillai M, Gollard R, Heim W, Swan F, Patel R, Dreiling L, Mo M, Malik I (2010) A randomized, placebo-controlled phase II study evaluating the reduction of neutropenia and febrile neutropenia in patients with colorectal cancer receiving pegfilgrastim with every2-week chemotherapy. Clin Colorectal Cancer 9:95-101

23. Bondarenko I, Gladkov OA, Elaesser R, Buchner A, Bias P (2013) Efficacy and safety of lipegfilgrastim versus pegfilgrastim: a randomized, multicenter, active-control phase 3 trial in patients with breast cancer receiving doxorubicin/docetaxel chemotherapy. BMC Cancer 13:386

24. Kuderer NM, Dale DC, Crawford J, Lyman GH (2007) Impact of primary prophylaxis with granulocyte colony-stimulating factor on febrile neutropenia and mortality in adult cancer patients receiving chemotherapy: a systematic review. J Clin Oncol 25:3158-3167

25. Caldwell DM, Ades AE, Higgins JP (2005) Simultaneous comparison of multiple treatments: combining direct and indirect evidence. BMJ 331:897-900

26. Madan J, Stevenson MD, Cooper KL, Ades AE, Whyte S, Akehurst $\mathrm{R}$ (2011) Consistency between direct and indirect trial evidence: is direct evidence always more reliable? Value Health 14:953-960

27. Pinto L, Liu Z, Doan Q, Bernal M, Dubois R, Lyman G (2007) Comparison of pegfilgrastim with filgrastim on febrile neutropenia, grade IV neutropenia and bone pain: a meta-analysis of randomized controlled trials. Curr Med Res Opin 23:2283-2295

28. Cooper KL, Madan J, Whyte S, Stevenson MD, Akehurst R (2009) Granulocyte colony-stimulating factors for prevention of febrile neutropenia following chemotherapy: systematic review and meta-analysis. University of Sheffield Health Economics and Decision Science. Available at: http://www.shef.ac.uk/scharr/sections/heds/ discussion-papers/907-1.292780. Accessed 23 Jun 2014

29. van Tulder M, Furlan A, Bombardier C, Bouter L (2003) Updated method guidelines for systematic reviews in the Cochrane Collaboration Back Review Group. Spine 28:1290-1299

30. Sung L, Beyene J, Hayden J, Nathan PC, Lange B, Tomlinson GA (2006) A Bayesian meta-analysis of prophylactic granulocyte colony-stimulating factor and granulocyte-macrophage colony-stimulating factor in children with cancer. Am J Epidemiol 163:811-817

31. National Comprehensive Cancer Network (2014) NCCN Clinical Practice Guidelines in Oncology: Myeloid Growth Factors, version 2.2014. Available at: www.NCCN.org. Accessed 2 Feb 2015

32. Balducci L, Al-Halawani H, Charu V, Tam J, Shahin S, Dreiling L, Ershler WB (2007) Elderly cancer patients receiving chemotherapy benefit from first-cycle pegfilgrastim. Oncologist 12:1416-1424

33. Fosså SD, Kaye SB, Mead GM, Cullen M, de Wit R, Bodrogi I, van Groeningen CJ, De Mulder PHM, Stenning S, Lallemand E, De Prijck L, Collette L (1998) Filgrastim during combination chemotherapy of patients with poor-prognosis metastatic germ cell malignancy. European Organization for Research and Treatment of Cancer, Genito-Urinary Group, and the Medical Research Council 
Testicular Cancer Working Party, Cambridge, United Kingdom. J Clin Oncol 16:716-724

34. Osby E, Hagberg H, Kvaloy S, Teerenhovi L, Anderson H, CavallinStahl E, Holte H, Myhre J, Pertovaara H, Bjorkholm M, Nordic Lymphoma G (2003) CHOP is superior to CNOP in elderly patients with aggressive lymphoma while outcome is unaffected by filgrastim treatment: results of a Nordic Lymphoma Group randomized trial. Blood 101:3840-3848

35. Romieu G, Clemens M, Mahlberg R, Fargeot P, Constenla M, Schutte M, Easton V, Skacel T, Bacon P, Brugger W (2007) Pegfilgrastim supports delivery of FEC-100 chemotherapy in elderly patients with high risk breast cancer: a randomized phase 2 trial. Crit Rev Oncol Hematol 64:64-72

36. del Giglio A, Eniu A, Ganea-Motan D, Topuzov E, Lubenau H (2008) XM02 is superior to placebo and equivalent to Neupogen in reducing the duration of severe neutropenia and the incidence of febrile neutropenia in cycle 1 in breast cancer patients receiving docetaxel/doxorubicin chemotherapy. BMC Cancer 8:332

37. Doorduijn JK, van der Holt B, van Imhoff GW, van der Hem KG, Kramer MH, van Oers MH, Ossenkoppele GJ, Schaafsma MR, Verdonck LF, Verhoef GE, Steijaert MM, Buijt I, Uyl-de Groot CA, van Agthoven M, Mulder AH, Sonneveld P (2003) CHOP compared with CHOP plus granulocyte colony-stimulating factor in elderly patients with aggressive non-Hodgkin's lymphoma. J Clin Oncol 21:3041-3050

38. Timmer-Bonte JN, de Boo TM, Smit HJ, Biesma B, Wilschut FA, Cheragwandi SA, Termeer A, Hensing CA, Akkermans J, Adang EM, Bootsma GP, Tjan-Heijnen VC (2005) Prevention of chemotherapy-induced febrile neutropenia by prophylactic antibiotics plus or minus granulocyte colony-stimulating factor in smallcell lung cancer: a Dutch randomized phase III study. J Clin Oncol 23:7974-7984

39. Trillet-Lenoir V, Green J, Manegold C, Von Pawel J, Gatzemeier U, Lebeau B, Depierre A, Johnson P, Decoster G, Tomita D, Ewen C (1993) Recombinant granulocyte colony stimulating factor reduces the infectious complications of cytotoxic chemotherapy. Eur J Cancer 29A:319-324

40. Zinzani PL, Pavone E, Storti S, Moretti L, Fattori PP, Guardigni L, Falini B, Gobbi M, Gentilini P, Lauta VM, Bendandi M, Gherlinzoni F, Magagnoli M, Venturi S, Aitini E, Tabanelli M, Leone G, Liso V, Tura S (1997) Randomized trial with or without granulocyte colonystimulating factor as adjunct to induction VNCOP-B treatment of elderly high-grade non-Hodgkin's lymphoma. Blood 89:3974-3979

41. Bui BN, Chevallier B, Chevreau C, Krakowski I, Peny AM, Thyss A, Maugard-Louboutin C, Cupissol D, Fargeot P, Bonichon F (1995) Efficacy of lenograstim on hematologic tolerance to MAID chemotherapy in patients with advanced soft tissue sarcoma and consequences on treatment dose-intensity. J Clin Oncol 13:2629-2636

42. Chevallier B, Chollet P, Merrouche Y, Roche H, Fumoleau P, Kerbrat P, Genot JY, Fargeot P, Olivier JP, Fizames C (1995) Lenograstim prevents morbidity from intensive induction chemotherapy in the treatment of inflammatory breast cancer. J Clin Oncol 13:1564-1571

43. Gebbia V, Testa A, Valenza R, Borsellino N, Cipolla C, Cannata G, Curto G, Latteri M, Florena M, Gebbia N (1993) A prospective evaluation of the activity of human granulocyte-colony stimulating factor on the prevention of chemotherapy-related neutropenia in patients with advanced carcinoma. J Chemother 5:186-190

44. Gebbia V, Valenza R, Testa A, Cannata G, Borsellino N, Gebbia N (1994) A prospective randomized trial of thymopentin versus granulocyte-colony stimulating factor with or without thymopentin in the prevention of febrile episodes in cancer patients undergoing highly cytotoxic chemotherapy. Anticancer Res 14:731-734

45. Grigg A, Solal-Celigny P, Hoskin P, Taylor K, McMillan A, Forstpointner R, Bacon P, Renwick J, Hiddemann W (2003) Openlabel, randomized study of pegfilgrastim vs. daily filgrastim as an adjunct to chemotherapy in elderly patients with non-Hodgkin's lymphoma. Leuk Lymphoma 44:1503-1508

46. Holmes FA, Jones SE, O'Shaughnessy J, Vukelja S, George T, Savin M, Richards D, Glaspy J, Meza L, Cohen G, Dhami M, Budman DR, Hackett J, Brassard M, Yang BB, Liang BC (2002) Comparable efficacy and safety profiles of once-per-cycle pegfilgrastim and daily injection filgrastim in chemotherapy-induced neutropenia: a multicenter dose-finding study in women with breast cancer. Ann Oncol 13:903-909

47. Park KH, Sohn JH, Lee S, Park JH, Kang SY, Kim HY, Park IH, Park YH, Im YH, Lee HJ, Hong DS, Park S, Shin SH, Kwon HC, Seo JH (2013) A randomized, multi-center, open-label, phase II study of once-per-cycle DA-3031, a biosimilar pegylated G-CSF, compared with daily filgrastim in patients receiving TAC chemotherapy for early-stage breast cancer. Invest New Drugs 31:1300-1306

48. Vose JM, Crump M, Lazarus H, Emmanouilides C, Schenkein D, Moore J, Frankel S, Flinn I, Lovelace W, Hackett J, Liang BC (2003) Randomized, multicenter, open-label study of pegfilgrastim compared with daily filgrastim after chemotherapy for lymphoma. J Clin Oncol 21:514-519

49. European Medicines Agency Committee for Medicinal Products for Human Use (CHMP) (2013) Assessment report: Lonquex. Available at: http://www.ema.europa.eu/docs/en_GB/document_library/ EPAR - Public assessment report/human/002556/WC500148382. pdf. Accessed $2 \overline{3}$ June 2014

50. The Cochrane Collaboration (2011) Cochrane handbook for systematic reviews of interventions, version 5.1.0. Available at: http:// handbook.cochrane.org/. Accessed 18 Feb 2014

51. Fu R, Gartlehner G, Grant M, Shamliyan T, Sedrakyan A, Wilt TJ, Griffith L, Oremus M, Raina P, Ismaila A, Santaguida P, Lau J, Trikalinos TA (2008) Conducting quantitative synthesis when comparing medical interventions: AHRQ and the Effective Health Care Program. Available at: http://www.ncbi.nlm.nih.gov/books/ NBK49407/. Accessed 23 June 2014 